\title{
UM CORPUS DE TRADUCÕES JURAMENTADAS - MATERIAL DE PESQUISA LINGÜÍSTICA, SOCIOLÓGICA E HISTÓRICA ${ }^{1}$
}

\author{
Francis Henrik Aubert* \\ Stella E. O. Tagnin*
}

\begin{abstract}
RESUMO: Este artigo apresenta um corpus de traduções juramentadas, que fará parte integrante do Projeto COMET. Descreve certos traços característicos da tradução juramentada no Brasil e da natureza do acervo visado. Delineia-se, ademais, a forma de classificação do material. Finalmente, aponta as diversas perspectivas de pesquisa que o material pode ensejar: a lingüística, a tradutológica, a sociológica e a histórica.
\end{abstract}

UNITERMOS: tradução; tradução juramentada; lingüística de corpus; lingüística comparada; lingüística contrastiva.

ABSTRACT: This paper presents a corpus of sworn translations, which is to become an integrate part of the COMET Project. Certain typical features of sworn translation in Brazil are described, as well as the nature of the material to be incorporated in the text bank. It sketches a form for classifying the textual material. Finally, it indicates the several research approaches this material will allow for: linguistic, translational, sociologic and historical.

KEYWORDS: translation; sworn translation; corpus linguistics; comparative linguistics; contrastive linguistics.

Universidade de São Paulo.

1 Uma versão anterior deste artigo foi apresentada no congresso Corpus Linguistics 2003, que se realizou em Lancaster, de 26 a 30 de abril de 2003, e publicada nos anais (Aubert \& Tagnin, 2003).

TradTerm, 10, 2004, p. 163-178 


\section{Introdução}

Sempre que, por qualquer motivo, um texto redigido em língua estrangeira tiver de ser utilizado para a prática de algum ato público - ou seja, tornar-se documento a ser usado em um país com idioma oficial diverso daquele em que o texto foi escrito - tal texto terá de vir acompanhado por uma tradução revestida de fé pública. Comumente, tais documentos são atestados de escolaridade (com vistas a intercâmbio de estudantes), certidões de nascimento, casamento ou óbito (para fins de naturalização, matrimônio ou herança), procurações, notas promissórias, contratos e estatutos sociais ou outros documentos comerciais ou societários (para utilização em situações de transações comerciais, financeiras e similares). Em princípio, porém, qualquer texto pode ser submetido a um procedimento de tradução dito "juramentado", caso tal texto, por qualquer motivo, deva ser processado por alguma repartição pública ou pelos tribunais. Assim, por exemplo, uma carta de amor terá de ser traduzida da forma juramentada, caso deva servir como prova documental em um processo de divórcio litigioso. A tradução de uma peça teatral pode dar origem a um processo por infração ao direito autoral, e, por conseguinte, até mesmo um texto literário poderá ter de ser re-elaborado no formato e de conformidade com as convenções da tradução juramentada, mediante sua retroversão ao idioma original, novamente para instruir o respectivo processo (vide, a propósito, Aubert, 1996).

Em grande número de países, uma tradução com fé pública é produzida por um corpo específico de profissionais devidamente habilitados pelo Poder Judiciário, pelo Ministério da Educação, pelo Ministério do Comércio e Indústria ou outro órgão ou instância da administração pública. No caso brasileiro, a competência para a seleção, nomeação e fiscalização desses profissionais - tradutores públicos e intérpretes comerciais, na sua designação formal, mais comumente referidos como tradutores juramentados - cabe às Juntas Comerciais de cada unidade da federação, e, no caso específico do Distrito Federal, ao Departamento Nacional do Registro do Comércio.

TradTerm, 10, 2004, p. 163-178 
Uma peculiaridade brasileira reside no fato de que os tradutores públicos, entre outras obrigações, devem fazer registrar, de acordo com determinadas normas, uma cópia integral de cada tradução juramentada que emitem em livros específicos. Quando da aposentadoria, exoneração ou falecimento do tradutor, esses livros são entregues à Junta Comercial da unidade da federação em que estão habilitados, com vistas a atender a eventuais solicitações de traslados ( $2^{\mathrm{a}} \mathrm{s}$ vias). Em vários casos, o material arquivado resultante dessa obrigação legal recobre um período igual ou superior a um século, envolvendo uma multiplicidade de idiomas.

\section{A natureza dos acervos de traduções juramentadas}

Em termos estritamente legais, as traduções juramentadas não constituem textos "independentes". No Brasil, uma tradução juramentada não pode ser utilizada em lugar do seu original; na realidade, a execução e a apresentação da tradução juramentada facultam ao texto original ${ }^{2}$ ser utilizado em caráter oficial. Por esse motivo, o original e a tradução são apresentados juntos à repartição, ao tribunal, ou outra instituição (escolas e universidades, bancos, seguradoras, departamentos de fiscalização do trânsito, etc.) à qual são destinados. Tal circunstância sugere que, ao menos em tese, as traduções juramentadas tenderão a ater-se mais próximas aos respectivos textos originais, que, em certo sentido, serão mais "literais" do que as traduções comuns, não oficiais. Este é, de fato, um traço definidor de traduções juramentadas em geral: sua intenção é a de auxiliar o receptor no entendimento do texto original e na moldura de seu contexto cultural de origem, não cabendo propor soluções que teriam sido apropriadas caso o texto tivesse sido originariamente produzido no quadro cultural e institucional da língua/cultura meta. Nos termos propostos por Venuti (1995), as traduções juramentadas

2 Ou uma cópia autenticada do original, mas nunca uma cópia não autenticada ou outra reprodução (fac-símile, impressão eletrônica, etc.).

TRADTERM, 10, 2004, p. 163-178 
166

adotam - ou deveriam adotar - estratégias e procedimentos de tradução "estrangeirizadoras" mais do que "domesticadoras". Assim, é de se esperar que o material a ser constituído como corpus do presente projeto oferecerá a possibilidade de testar essa hipótese, e, mais especificamente, de identificar em que medida outros fatores, para além do "modo juramentado" de traduzir, tendem a estimular ou, ao contrário, a neutralizar a "regra de estrangeirização" (p. ex., tipologia textual, direção tradutória, assunto, etc.).

As traduções juramentadas não constituem um universo fechado. Uma grande variedade de textos produzidos originariamente em determinado idioma tem por intenção final a sua circulação internacional, em um ou mais outros idiomas. Assim, já na elaboração dos originais, pode-se prever que a construção textual (nos planos terminológico, fraseológico ou mesmo na sua "gramática de texto") leve em conta essa segunda etapa, influenciando o modo de dizer no espaço lingüístico-cultural de partida. Do mesmo modo, é de se prever que as formas de dizer, em determinado idioma/país, as realidades culturais, jurídicas, comerciais e escolares de outros países (para citar apenas as áreas mais comumente abordadas pela tradução juramentada), tenham sido, em grande parte, influenciadas pelas soluções encontradas e, paulatinamente, cristalizadas pela praxe dos tradutores públicos, mesmo em situações que não envolvam diretamente a operação tradutória ou que exijam apenas uma operação tradutória não-oficial. Tome-se como exemplo a tradução consagrada do "sócio-quotista" brasileiro por "quotaholder", em vez do seu equivalente mais próximo em inglês, "shareholder". Considera-se, portanto, que um conjunto de estudos terminológicos, fraseológicos, textuais e tradutológicos, sincrônicos e diacrônicos, efetuados sobre os acervos disponiveis nos arquivos das Juntas Comerciais, poderá fornecer subsídios para uma compreensão ampla das questões tradutórias e interculturais que incluam, em uma das pontas (fonte e/ou meta), o português brasileiro, e não apenas na própria modalidade juramentada da tradução.

Convém, neste ponto, ressalvar que o material que constituirá o corpus apresenta uma limitação. Embora os tradutores públicos devam arquivar uma cópia integral de cada tradução,

TRadTerm, 10, 2004, p. 163-178 
inexiste qualquer requisito equivalente quanto a cópias dos textos originais. Assim, os livros de tradutores que alimentarão o projeto aqui descrito não oferecerão um corpus estritamente paralelo, apenas comparativo, e o original, salvo exceção, somente poderá ser inferido a partir das traduções.

Essa limitação poderá, por vezes, constituir um problema. Um trecho inusitado em uma tradução pode, evidentemente, indicar um erro ou uma falha do tradutor. Alternativamente, pode ser indicativo de uma tentativa de reproduzir algo inusitado existente no original, visto que a tradução juramentada, como já foi dito aqui, deve (ou é entendida como devendo) "espelhar" o original, não melhorá-lo (embora, com certa freqüência, os textos originais só teriam a ganhar com tais melhorias) (vide Aubert, 1996).

\section{O Projeto COMET e o Corpus de Traduções Juramentadas}

Tal como caracterizado em Tagnin (neste volume), o Projeto COMET compreende três subcorpora: um corpus Técnico-Científico (Tagnin, 2003b), um corpus de Aprendizes (Tagnin, 2003a) e um corpus de Tradução. Aqui, cabe destacar o Corpus de Tradução, no âmbito do qual se insere o Corpus de Traduções Juramentadas (CTJ) com as seguintes características:

\subsection{Caracterização do Corpus}

1. O acervo a ser analisado e que dará suporte ao CTJ é aquele disponível nos arquivos da Junta Comercial do Estado de São Paulo (JUCESP);

2. O objetivo primordial do corpus é fornecer subsídios para estudos nas áreas de tradução, lexicologia, terminologia e fraseologia comerciais e jurídicas. Em uma etapa inicial, a base de dados será alimentada com textos traduzidos do alemão, do espanhol, do francês, do inglês e do italiano para o português brasileiro ou do português brasileiro para qualquer um desses idiomas;

TradTerm, 10, 2004, p. 163-178 
3. Os principais usuários do material serão estudantes, pesquisadores e docentes do curso de tradução, lexicógrafos e terminólogos. No entanto, visto que todos os textos serão inseridos na íntegra, o material também será de utilidade para pesquisadores voltados para a análise do discurso ou, ainda, para estudos de lingüística contrastiva. Os produtos dos esforços de pesquisa, por sua vez, deverão atender, em especial, aos próprios profissionais da tradução, juramentada ou não;

4. Conforme explicado adiante, apenas ocasionalmente haverá textos paralelos (ou seja, conjuntos de originais e suas respectivas traduções); assim, o corpus terá essencialmente uma vocação para estudos em paralelo. Será, ainda, um corpus aberto, visto que outros materiais poderão ser continuamente acrescidos à medida que novos materiais forem disponibilizados e processados;

5. Uma questão importante decorre da natureza pública da tradução juramentada. Em tese, inexistem restrições decorrentes da legislação que protege o direito de autor. Por outro lado, a despeito dessa dimensão pública, algumas traduções juramentadas podem ter sido executadas para fins de instruir processos "sob segredo de justiça". Assim, será de fundamental importância elaborar procedimentos de acesso que assegurem alguma proteção ao material constante do corpus e, conforme o caso, disponibilizar alguns dos materiais com apagamento ou mascaramento dos elementos identificadores das partes envolvidas e/ou das situações específicas (endereços, números de registro, varas, comarcas, et simil);

6. As traduções juramentadas arquivadas na Junta Comercial estão organizadas sob forma de "livros", identificados pelo nome do tradutor público e pelo idioma estrangeiro do qual ou para o qual as traduções foram executadas. Assim, por exemplo, um tradutor público habilitado para inglês, francês e espanhol terá três séries de livros (de até 400 folhas cada uma), uma série para cada idioma estrangeiro. Se determinado original contiver material textual em mais de um idioma estrangeiro, a tradução virá normalmente registrada no

TRadTerm, 10, 2004, p. 163-178 
livro que corresponde ao idioma quantitativamente predominante no texto original ou, alternativamente, no volume correspondente ao idioma oficial, se houver, do país em que o documento original foi emitido; ${ }^{3}$

7. Os principais idiomas estrangeiros representados (como linguas fonte ou línguas meta) no corpus são o inglês, o espanhol, o francês, o alemão e o italiano (a grosso modo, nessa ordem). Também se encontra algum material relativamente significativo para o árabe, o chinês, o coreano, o dinamarquês, o grego, o hebraico, o holandês, o húngaro, o japonês, o latim, o norueguês e o russo, embora para esses idiomas, o volume efetivo ainda esteja para ser avaliado.

\subsection{A conversão dos textos para o formato eletrônico - especificidades}

Uma das principais dificuldades iniciais será a conversão do material para o formato eletrônico. Até o início dos anos 50 do século XX, a maioria dos tradutores copiava ou fazia copiar à mão as traduções no livro de registros. A partir de meados da década de 50 e até princípios dos anos 70, boa parte das tradu-

3 Os textos lingüisticamente híbridos são, de fato, bastante usuais. Uma subsidiária de uma holding norte-americana, constituída no Grão-Ducado de Luxemburgo, terá o seu Contrato Social redigido em inglês, acompanhado de uma versão em francês, e com seu registro também em francês, salvo se um dos signatários for residente na Itália, caso em que um dos reconhecimentos de firma poderá vir expresso em italiano. Em um caso mais extremo encontrado no material do acervo, um conhecimento de embarque foi observado como tendo sua parte impressa escrita em inglês, seus diversos campos preenchidos em "portunhol" (provavelmente indicando uma tentativa canhestra de produzir texto em português); o carimbo da transportadora continha texto em alemão, o endereço da empresa de navegação estava vazado em norueguês, mas a legalização havia sido efetuada no Cantão de Ticino, Suiça, e, portanto, estava formulada em italiano. Visto que o texto de base encontrava-se redigido em inglês, essa tradução apareceu inserida no livro de registro para o idioma inglês do tradutor em questão.

TradTerm, 10, 2004, p. 163-178 
170

ções encontradas no acervo se apresentava como cópias carbono, ou, alternativamente, como cópias por "gelatina", conforme era usual nos cartórios da época. A cópia reprográfica tornouse usual apenas a partir de princípios da década de 80. Em termos de tratamento computacional, contudo, a qualidade dessas cópias nem sempre é tal que permita a realização do escaneamento eletrônico sem exigir um volume excessivo de revisão. Assim, em grande medida, o material constante do acervo terá de ser transcrito, em uma operação que, como se sabe desde o tempo dos copistas medievais, é prenhe de riscos de erro, de deslizes, lapsos e dos efeitos do desejo, consciente ou subconsciente, de "melhorar" ou "atualizar" o texto. O fato de que, ao longo do período de tempo representado pelo acervo (1902-2002), o português brasileiro passou por duas grandes reformas ortográficas não torna essa tarefa computacional menos penosa. No entanto, a variedade do material e os frutos potenciais para a pesquisa são de tal monta que se percebe como recompensador o esforço a ser exigido (inclusive em termos de uma supervisão rigorosa e constante da transcrição eletrônica).

Devido ao volume do material a ser trabalhado, bem como a necessidade - em alguns casos, premente - de restauro de parte desse material, prevê-se que seu processamento seja efetuado por lotes. Uma hipótese preliminar - sujeita a eventuais alterações a depender do efetivo volume e da natureza do material, ainda a serem determinados de maneira mais precisa - prevê a seguinte seqüenciação:

1. traduções produzidas nos últimos 30 anos (1972-2002);

2. traduções produzidas no período de 1935-1971; e

3. traduções produzidas no período de 1902-1934.

Tão logo um volume representativo do primeiro lote tenha sido processado, este será disponibilizado na Web como um corpus piloto (sujeito às restrições de sigilo referidas acima). Subseqüentemente, o corpus será atualizado periodicamente, à medida que novos textos forem preparados para a leitura eletrônica.

TRadTerm, 10, 2004, p. 163-178 


\subsection{As tipologias textuais}

Embora, em uma determinada situação, praticamente qualquer texto possa vir a ser submetido a um processo de "tradução juramentada" (vide Introdução), a maioria das traduções disponiveis no acervo da JUCESP pode ser dividida em quatro grupos principais: (a) documentos pessoais (de identidade, certidões de nascimento, casamento, divórcio e óbito, documentos escolares, e similares); (b) documentos societários (contratos sociais, deliberações societárias, atas de assembléias de acionistas, certificações de secretários, de tabeliães ou de oficios de registro de títulos e documentos, etc.); (c) documentos comerciais e financeiros (conhecimentos de embarque, contratos em geral - compra e ven$\mathrm{da}$, arrendamento e outros financiamentos, licenciamento de marcas, transferência de tecnologia -, notas promissórias e outros títulos negociáveis); e (d) documentos jurídicos propriamente ditos (petições, cartas rogatórias, sentenças e acórdãos).

Obviamente, os grupos (b), (c) e (d) apresentam intersecções significativas em terminologia e fraseologia, embora suas finalidades precipuas e os atores envolvidos sejam algo diversos. Textos que tratam diretamente de assuntos atinentes à tecnologia industrial são relativamente raros, salvo o caso de registros de patentes e dos anexos descritivos presentes em contratos de transferência de tecnologia. Mesmo esses, no entanto, contêm, em maior ou menor grau, termos e frases que pertencem às linguagens de especialidade dos domínios jurídico e comercial.

\subsection{A estrutura do corpus}

Com vistas a atender às necessidades dos estudos comparativos e contrastivos previstos, na estruturação do material a categoria idioma terá precedência. Os dois niveis seguintes serão, pela ordem, a data (ano) e a tipologia e a subtipologia textuais. Assim, por exemplo: ${ }^{4}$

4 Obviamente, a complexidade real é maior do que a ilustrada na lista abaixo. Assim, podem ocorrer hibridismos (por exemplo, um modelo de

TradTerm, 10, 2004, p. 163-178 
172

\section{Inglês}

2000

\section{Documentos Pessoais}

Certidões de nascimento, óbito, casamento e divórcio

Históricos Escolares

Documentos Comerciais e Financeiros

Demonstrativos Financeiros

Conhecimentos de Embarque

Notas Promissórias

Documentos Societários

Contratos Sociais

Atas de Assembléias e de Reuniões do Conselho

de Administração

Documentos Jurídicos

Petições e atos similares de instituição de processo

Sentenças e acórdãos

Cartas rogatórias

Instrumentos de Procuração

Alemão

2000

\section{Documentos Pessoais}

Certidões de nascimento, óbito, casamento e divórcio

Históricos Escolares

Documentos Comerciais e Financeiros

etc....

nota promissória inserido em um contrato de compra e venda). Um laudo arbitral, embora emitido por uma entidade não pertencente ao Poder Judiciário (freqüentemente, uma arbitragem é conduzida sob a égide de uma Câmera do Comércio), tem todas as caracteristicas de um documento jurídico. Uma certidão de divórcio pode ser emitida como parte integrante (apostilamento) de uma certidão de casamento e, nesse sentido, integra a categoria de documentos pessoais; já uma sentença de divórcio constitui, em vários países (inclusive no Brasil) um documento jurídico, emitido pelo Poder Judiciário.

TradTerm, 10, 2004, p. 163-178 


\subsection{A nomeação dos arquivos e o cabeçalho}

Cada texto será identificado por um código indicativo da direção tradutória, data, tipologia textual e número do texto. Assim, por exemplo, DP902CN0001 sig-nifica: do alemão para o português, ano da tradução 1902, certidão de nascimento, texto n. ${ }^{\circ} 0001$ da categoria. Tal representação permitirá abrigar até 9.999 textos em cada categoria. O total potencial provavelmente jamais será atingido para a maioria das categorias, mas, a depender do material novo a ser acrescido ao longo do tempo, é bem possivel que essa expectativa se cumpra em algumas delas, em particular, na relação tradutória com o inglês, que é, de longe, a língua fonte predominante.

Para que o usuário do corpus possa selecionar os textos mais relevantes para sua pesquisa (por ex. por data, por idioma, por assunto), cada texto deve ser precedido por um "cabeçalho" conjunto de informações sobre os textos representadas em linguagem computacional amigável. Com base no cabeçalho criado para o Translational English Corpus (TEC), ${ }^{5}$ pelo Instituto de Ciências e Tecnologia da Universidade de Manchester (UMIST), Inglaterra, foi desenvolvida, pelo Projeto Lácio-Web (Aluísio et al. 2003), do qual o COMET é parceiro, uma versão mais elaborada, que proverá informações mais detalhadas sobre as amostras, sobretudo quanto à direção tradutória, idioma do texto fonte, idioma do texto meta, data da tradução, nome do tradutor, seu sexo e origem (se disponivel), o tipo de texto, a extensão total do texto e seu assunto, além de toda a sorte de informações bibliográficas (data e local de publicação, editor, etc., quando relevantes).

A inserção do cabeçalho exige uma análise cuidadosa do material. É fundamental que o cabeçalho seja elaborado corretamente, i.e., de acordo com dados pertinentes e consistentes para a Lingüistica de Corpus e os Estudos em Tradução. Tal condição visa ao suporte à busca automática, uma vez que os dados do cabeçalho servirão como identificadores para a seleção de textos a serem submetidos a pesquisa com o auxílio de ferramentas eletrônicas de busca. Ou seja, os textos poderão ser recuperados

5 www2.umist.ac.uk/ctis/research/TEC/tec_home_page.htmv

TradTerm, 10, 2004, p. 163-178 
174

por idioma, por tipologia textual, por data, por tradutor, por assunto, etc., ou por qualquer combinatória desses parâmetros.

\section{Potencialidades de pesquisa}

A despeito de algumas limitações referidas nos parágrafos precedentes, espera-se que o material resultante do acervo JUCESP proporcione um amplo conjunto de informações relevantes à pesquisa lingüistica e histórica.

Um exame ainda inicial dos materiais do acervo indica que cerca de $3 / 4$ das traduções foram realizadas da língua estrangeira para o português, o $1 / 4$ restante correspondem a traduções do português para as línguas estrangeiras e, ocasionalmente, entre línguas estrangeiras. A despeito da clara diferença na distribuição, as dimensões do material - cerca de 3.000 volumes, ou seja, aproximadamente 1 milhão de páginas, representando um século de traduções oficiais - deverá poder oferecer amostras textuais suficientes para uma ampla investigação lingüística, estilística, tradutológica, intercultural e histórica em ambas as direções tradutórias (de e para o português), e possibilitar comparações relevantes.

Para fins terminológicos, espera-se que o corpus de traduções juramentadas proporcione uma vasta gama de situações de tradução, desvelando tanto as estratégias subjacentes quanto as soluções efetivamente propostas. $\mathrm{O}$ fato de diferentes línguas fonte e meta estarem envolvidas também facultará uma boa base de comparação, permitindo, por exemplo, verificar em que medida determinada língua fonte ou meta exerce certas influências sobre as opções terminológicas dos tradutores.

Os estudos terminológicos possibilitados pelo corpus não derivarão apenas dos textos das traduções em si. Alguns tradutores públicos, ao longo de suas carreiras, montaram seus próprios glossários, e um desses (contendo perto de 2.000 termos) já foi disponibilizado para o CITRAT/USP pelos herdeiros de um tradutor público, recentemente falecido, do idioma alemão. O material textual a ser inserido na base de dados do COMET servirá para validar, rever e/ou modificar as soluções propostas, mediante uma comparação entre o glossário, com os usos efeti-

TradTerm, 10, 2004, p. 163-178 
vos, e os contextos correspondentes encontrados nas traduções juramentadas do referido tradutor. Em etapa subseqüente, as soluções terminológicas validadas para a produção deste tradutor específico poderão ser comparadas com aquelas encontradas nos livros de outros tradutores, bem como com aquelas propostas/recomendadas por Câmaras do Comércio, glossários monolíngües em alemão e em português brasileiro, e assim por diante.

Expectativas similares podem ser entretidas em relação à fraseologia, embora, sendo a fraseologia intimamente vinculada à estilística e aos traços pertinentes do idiomatismo de cada língua, se possa esperar que o subcorpus de versões proporcione uma base mais segura de análise comparada do que as traduções para o português brasileiro provindas de diversos idiomas estrangeiros e/ou de diversos países usuários de um mesmo idioma estrangeiro.

Considere-se, por exemplo, a expressão relativamente cristalizada que usualmente encerra o preâmbulo a um contrato brasileiro padrão: "As partes qualificadas supra têm entre si justo $e$ acordado o que segue". Embora os textos originais não estejam disponiveis, a previsibilidade desta expressão é tal que poderá ser facilmente inferida nas diversas versões a serem analisadas. Assim, é de esperar que ela reapareça com soluções diversificadas em muitas traduções diferentes e em grande variedade de idiomas, proporcionando uma base para uma pesquisa típica(mente)? de estilística comparada, um pouco no sentido originariamente concebido por Vinay e Darbelnet (1958).

$\mathrm{Na}$ ausência dos textos originais correspondentes, uma observação direta dos procedimentos de tradução envolvidos não poderá ser conduzida de forma sistemática. ${ }^{6}$ No entanto, a ob-

6 Ocasionalmente, os clientes de traduções juramentadas solicitam que o texto original seja inserido junto à tradução, em duas colunas paralelas. Além disso, um volume representativo de traduções juramentadas se faz sobre textos originais padronizados (por exemplo, passaportes, carteiras de habilitação), em que o texto é fundamentalmente o mesmo, excetuados os dados pessoais de seu portador. Aqui, bastará ter acesso a um de tais textos originais padronizados em cada idioma para se efetuar uma observação direta dos procedimentos de tradução adotados pelos diferentes tradutores.

TradTerm, 10, 2004, p. 163-178 
176

servação das estruturas lexicais e sintáticas, e suas respectivas freqüências nos materiais traduzidos em confronto com suas freqüências correspondentes em textos originais autênticos e em traduções simples (isto é, "não-juramentadas"), deverá revelar o grau de "contaminação" estrutural (ou de desvio literalizante) das traduções juramentadas de e para o português brasileiro. Por sua vez, essa distinção "de e para" é de certa relevância. Com efeito, uma das hipóteses iniciais é a de que as estratégias de tradução não serão as mesmas, e que variarão em função da direção tradutória. ${ }^{7}$

Também de certo interesse será a observação das soluções tradutórias, que se consagraram como "tradutês" padrão de traduções do português brasileiro para idiomas estrangeiros como marcadores de especificidades culturais, jurídicas e institucionais brasileiras, tais como: (a) o uso generalizado de birth certificate como tradução para o inglês de certidão de nascimento, em vez de birth registration certificate; ${ }^{8}$ (b) ou o nome oficial do país como Federative Republic of Brazil, embora Federal Republic of Brazil tivesse sido uma solução idiomaticamente mais apropriada em inglês. Evidentemente, a mesma linha de observação poderá ser adotada na direção tradutória oposta. É interessante, por exemplo, constatar que um county estadunidense vem geralmente traduzido como "condado", embora o sistema institucional brasileiro tenha um correspondente bastante próximo: "comarca". E, por motivos que ainda merecem investigação mais aprofundada, os consulados brasileiros no exterior, quando situados nos EUA ou no Canadá, tendem a identificar o notary public como "notário público", e, se situados no Reino Unido, como "tabelião público".

7 Em sua tese de doutorado, Sonia T. Gehring (1998), trabalhando com tipologias textuais e tradutórias diferentes (ciências sociais), fornece comprovação estatística de que as traduções do inglês para o português brasileiro são, em certo sentido, mais "literais" (ou "estrangeirizadoras"), ao passo que textos equivalentes traduzidos do português brasileiro para o inglês tendem a ser mais "livres" (ou mais "domesticados").

8 Nos EUA, a birth certificate é emitido pelo médico ou parteira e a birth registration certificate pelo equivalente ao nosso Registro Civil - na realidade, Bureau of Vital Statistics, vinculado ao equivalente à Secretaria Estadual da Saúde.

TRadTerm, 10, 2004, p. 163-178 
Na primeira etapa da organização do corpus dever-se-á cobrir um período correspondente aos últimos trinta anos (1972/ 2002). Em etapas subseqüentes, os livros de tradutores públicos de períodos anteriores serão progressivamente incluídos até cobrir todo o século 20. Mesmo a etapa inicial, porém, deverá proporcionar elementos suficientes para certas pesquisas de natureza diacrônica, provavelmente não em termos de estrutura lingüística, mas, certamente, em terminologia e, muito possivelmente, em procedimentos e estratégias de tradução. Nessa faixa de tempo, vários fatores extralingüisticos relevantes provavelmente terão exercido influências marcantes, notadamente o processo que culminou com a promulgação da Constituição de 1988 (e as novas instituições e os novos conceitos jurídicos decorrentes da atual Carta Magna); a abertura da economia brasileira, a partir de 1990; a intensificação dos intercâmbios comerciais e culturais com outros países latino-americanos, em especial no quadro do Mercosul; a crescente afirmação de direitos de propriedade intelectual, inclusive em processos judiciais que, por sua vez, tendem a impelir as traduções para uma posição mais próxima aos textos originais, de modo a minimizar o risco de infringir ou parecer infringir tais direitos pela intromissão de uma co-autoria mais explícita e, usualmente, indesejada; e, muito obviamente, a passagem do trabalho do tradutor da máquina-de-escrever para o computador pessoal, como ferramenta de escrita, de editoração, de revisão, de pesquisa terminológica e de exploração de novas estratégias, inclusive a tradução intersemiótica. Se tais fatores forem efetivamente relevantes para a produção dos tradutores públicos, é cabível conceber podermos observar seus reflexos e suas refrações nos materiais traduzidos, comparando-se as traduções produzidas em meados dos anos 70 com aquelas geradas na segunda metade dos anos 90 .

As considerações que precedem também apontam para outras potencialidades de pesquisa, para além do domínio dos estudos da linguagem senso estrito. A estreita vinculação entre a tradução pública e as esferas política, institucional, econômica e jurídica sugere que um material que abarca todo um século de produção textual deverá também carregar as marcas dos processos históricos vivenciados pela comunidade em que tais tradu-

TradTerm, 10, 2004, p. 163-178 
178

ções foram executadas e recebidas: a Primeira República; os diversos interlúdios ditatoriais alternando com governos civis; as duas guerras mundiais e a participação do Brasil nesses conflitos; as diversas ondas migratórias, em especial da Espanha, de Portugal, da Itália, do Levante, do Japão e, mais recentemente, da Coréia; o início da industrialização do país, e sua transformação de sociedade rural em urbana; as idas e vindas da economia. Nesse ponto, o projeto ramifica-se em uma promissora cooperação inter e transdisciplinar com historiadores, sociólogos e antropólogos, pelo menos.

\section{Referências bibliográficas}

ALUÍSIO, S.M., PINHEIRO, G.M., FINGER, M., NUNES, M.G.V., TAGNIN, S.E.O. (2003) The Lácio-Web Project: overview and issues in Brazilian Portuguese corpora creation. In Proceedings of Corpus Linguistics 2003, Lancaster, UK.

AUBERT, F. H. (1996) Translation Typology: the Case of 'Sworn Translations'. In COUlTHARD, M., DE BAUBETA, P.A.O. (Org) Theoretical Issues and Practical Cases in Portuguese-English Translations. Edwin Mellen Press.

GEHRING, S.T. (1998) As modalidades de tradução inglês/português: correlações bidirecionais. Dissertação não publicada. Universidade de São Paulo.

TAGNIN, S.E.O. (2003a) A multilingual learner corpus in Brazil. In the Proceedings of the Workshop on Learner Corpora at Corpus Linguistics 2003, Lancaster.

- (2003b) Os Corpora: instrumentos de auto-ajuda para o tradutor. Cadernos de Tradução IX - 2002/1, número especial sobre Tradução e Corpora. Florianópolis: Universidade Federal de Santa Catarina.

. (2004) Um Corpus Multilíngüe para Ensino e Tradução - o

COMET: da construção à exploração. Neste volume.

VENUTI, L. (1995) The translator's invisibility. London, Rutledge.

VINAY, J., DARBELNET, J. P. (1958) Stylistique comparée du français et de l'anglais. Paris, Didier.

TradTerm, 10, 2004, p. 163-178 